\title{
Immunotherapeutic approaches to ovarian cancer treatment
}

\author{
Cariad Chester', Oliver Dorigo ${ }^{2}$, Jonathan S Berek ${ }^{2}$ and Holbrook Kohrt ${ }^{1 *}$
}

\begin{abstract}
Despite advances in combinatorial chemotherapy regimens and the advent of intraperitoneal chemotherapy administration, current therapeutic options for ovarian cancer patients are inadequate. Immunotherapy offers a novel and promising therapeutic strategy for treating ovarian tumors. Following the demonstration of the immunogenicity of ovarian tumors, multiple immunotherapeutic modalities have been developed. Antibody-based therapies, immune checkpoint blockade, cancer vaccines, and chimeric antigen receptor-modified $T$ cells have demonstrated preclinical success and entered clinical testing. In this review, we discuss these promising immunotherapeutic approaches and emphasize the importance of combinatorial treatment strategies and biomarker discovery.
\end{abstract}

Keywords: Ovarian cancer, ID8, Antibody, TAM, Immune checkpoint blockade, IDO, Cancer vaccine, ACT

\section{Introduction}

In 2012, there were an estimated 239,000 new cases of ovarian cancer worldwide leading to over 140,000 deaths [1]. Epithelial ovarian cancer is the fourth most common cause of cancer-related death in women in the developed world, where it is also the leading cause of death from gynecological malignancies [2]. The lethality of ovarian cancer is in part due to the difficulty of early detection. Ovarian cancer causes few perceptible symptoms when localized to the ovary. Due to the asymptomatic nature of early disease, most patients do not seek medical care until the disease has progressed beyond the ovaries into the abdomen and pelvis [3]. Nearly $75 \%$ of patients present with stage III and IV ovarian cancer [4]. Management of ovarian cancer primarily includes cytoreductive surgery and platinum-based chemotherapy. While clinical remissions are obtainable, the majority of patients will relapse and die of disease, with a 5-year survival of approximately $30 \%$ [5]. Novel therapies need to be integrated into ovarian cancer treatment strategies to achieve durable clinical outcomes.

In the last two decades, advances in the understanding of ovarian cancer immunogenicity have opened the door

\footnotetext{
* Correspondence: kohrt@stanford.edu

'Department of Medicine, Division of Oncology, Stanford University School of Medicine, Stanford, CA, USA

Full list of author information is available at the end of the article
}

to immunotherapeutic approaches to ovarian cancer treatment. A crucial early step in establishing the validity of ovarian cancer immunotherapy was the observation that $\mathrm{CD}^{+}$tumor-infiltrating $\mathrm{T}$ cells correlated with increased overall survival [6]. Later work confirmed the importance of tumor-infiltrating lymphocytes (TILs) and specifically identified the $\mathrm{CD}^{+}, \mathrm{CD}^{+} \mathrm{T}$ cells as important antitumor effectors [7]. The identification of tumorassociated antigens (TAAs) lent additional support to an immunotherapeutic treatment strategy. TAAs aberrantly up-regulate in tumor tissue and ascites of ovarian cancer patients and include members of the cancer-testis antigen family (e.g. MAGE-A4 and NY-ESO-1), growth-activating receptors (e.g. HER2/neu), folate receptor alpha (FR $\alpha)$, p53, and CA125 [8-10]. These markers are potential therapeutic targets for eliciting an immune response specific to ovarian cancer and effecting immune-mediated tumor rejection. The Food and Drug Administration (FDA) has approved immunotherapies for prostate cancer, advanced kidney cancer, lymphoma, and metastatic melanoma, but only recently have immunotherapies targeting ovarian cancer entered clinical testing (Table 1). In this review, we discuss advances in immunotherapeutic approaches to ovarian cancer. We divide therapeutic strategies into four categories: antibodies, immune checkpoint inhibitors, vaccines, and adoptive cell therapy (ACT). 
Table 1 Key trials in ovarian cancer immunotherapy

\begin{tabular}{|c|c|c|c|c|c|}
\hline Study & Patients & Treatment & $\begin{array}{l}\text { \# of } \\
\text { Patients }\end{array}$ & Response & Survival \\
\hline \multirow{5}{*}{$\begin{array}{l}\text { Vald, Edwards Cancer } \\
\text { Immunol Immunother } \\
2010\end{array}$} & \multirow{5}{*}{$\begin{array}{l}\text { Recurrent, platinum resistant } \\
\text { ovarian cancer }\end{array}$} & Interleukin-2 i.p. & \multirow[t]{5}{*}{24} & CR: 4 & Median Survival: \\
\hline & & \multirow[t]{4}{*}{$6 \times 10^{5} \mathrm{IU} / \mathrm{ml}$ weekly $\times 16$} & & PR: 2 & Non-Responder: \\
\hline & & & & \multirow[t]{3}{*}{ SD: 7} & 1.5 years \\
\hline & & & & & Responders: not reached \\
\hline & & & & & (24 -120+ months) \\
\hline Hodi, Dranoff & \multirow{3}{*}{$\begin{array}{l}\text { Recurrent metastatic ovarian } \\
\text { cancer }\end{array}$} & CTLA-4 Blockade: & \multirow[t]{3}{*}{9} & CR: 0 & Duration of Response: \\
\hline \multirow[t]{2}{*}{ PNAS 2008} & & \multirow[t]{2}{*}{ Ipilupimab i.v. 3 mg/kg q 2 - 3 months } & & PR: 1 & SD: $2,4,6+$ Months \\
\hline & & & & SD: 3 & PR: $35+$ Months \\
\hline Diefenbach, Dupont & \multirow{3}{*}{$\begin{array}{l}\text { "High Risk" ovarian cancer after } \\
\text { surgery and } 1^{\text {st }} \text { line chemo }\end{array}$} & \multirow{3}{*}{$\begin{array}{l}\text { NY-ESO-1b peptide (position 157-165; } \\
100 \mu \mathrm{g})+0.5 \mathrm{~mL} \text { Montanide ISA-51 } \\
\text { s.c. q } 3 \text { weeks } \times 5\end{array}$} & \multirow[t]{3}{*}{9} & \multirow[t]{3}{*}{ NA } & Median PFS: 13 months \\
\hline \multirow[t]{2}{*}{ Clin Cancer Res 2008} & & & & & $6 / 9$ patients recurred \\
\hline & & & & & $\begin{array}{l}3 \text { patient disease free } \\
\text { after } 25,38 \text {, and } 52\end{array}$ \\
\hline \multirow{6}{*}{$\begin{array}{l}\text { Fujita,Tanaka Clin } \\
\text { Cancer Research } 1995\end{array}$} & \multirow{6}{*}{$\begin{array}{l}\text { NED after surgery and } 1^{\text {st }} \text { line } \\
\text { chemo }\end{array}$} & \multirow[t]{6}{*}{$1.0-4.4 \times 10^{9} \mathrm{TIL}$ after $1^{\text {st }}$ line chemo } & $13 \mathrm{TIL}$ & \multirow[t]{6}{*}{ NA } & 3-year DFS: \\
\hline & & & \multirow[t]{5}{*}{11 Control } & & TIL: $82.1 \%$ \\
\hline & & & & & Control: $54.5 \%$ \\
\hline & & & & & $\begin{array}{l}\text { 3-year DFS, residual } \\
\text { disease after surgery }\end{array}$ \\
\hline & & & & & TIL: $76.2 \%$ \\
\hline & & & & & Control: $33.3 \%$ \\
\hline Chu, June & \multirow{3}{*}{$\begin{array}{l}\text { Consolidation after } 1^{\text {st }} \text { line } \\
\text { treatment or secondary debulking }\end{array}$} & \multirow{3}{*}{$\begin{array}{l}\text { Her-2/neu, hTERT, PADRE-loaded } \\
\text { Dendritic cells +/- Cyclophosphamide }\end{array}$} & \multirow{3}{*}{11} & \multirow[t]{3}{*}{ NA } & 5 recurrences \\
\hline \multirow[t]{2}{*}{$\begin{array}{l}\text { Cancer Immunol } \\
\text { Immunother } 2012\end{array}$} & & & & & $\begin{array}{l}6 \text { patients NED } \\
\text { at } 36 \text { months }\end{array}$ \\
\hline & & & & & 3-year OS 90\% \\
\hline Odunsi, Jaeger & \multirow{3}{*}{$\begin{array}{l}\text { Consolidation after } 1^{\text {st }} \text { line } \\
\text { treatment }\end{array}$} & I.d. rV-NY-ESO-1, & \multirow[t]{3}{*}{22} & \multirow[t]{3}{*}{ NA } & PFS: 21 months \\
\hline \multirow[t]{2}{*}{ PNAS 2012} & & $3.1 \times 10^{7}$ PFU, monthly s.c. & & & OS: 48 months \\
\hline & & rF-NY-ESO-1, $7.41 \times 10^{7}$ PFU for 6 mo. & & & \\
\hline Rahma, Khleif & \multirow{2}{*}{$\begin{array}{l}\text { HLA-A2.1 + stage III, IV, } \\
\text { or recurrent ovarian }\end{array}$} & \multirow{2}{*}{$\begin{array}{l}\text { Arm A: s.C. wt p53:264-272 peptide } \\
\text { with Montanide and GM-CSF. }\end{array}$} & \multirow[t]{7}{*}{21} & NA & Arm A: \\
\hline $\begin{array}{l}\text { Cancer Immunol } \\
\text { Immunother } 2012\end{array}$ & & & & & $\begin{array}{l}\text { Immune responses } \\
\text { 9/13 patients (69\%), } \\
\text { PFS: } 4.2 \text { months }\end{array}$ \\
\hline & $\begin{array}{l}\text { Cancer over-expressing the } \\
\text { p53 protein, no evidence of }\end{array}$ & $\begin{array}{l}\text { Arm B: i.v. wt p53:264-272 } \\
\text { peptide-pulsed dendritic cells IV }\end{array}$ & & & OS: 40.8 months \\
\hline & & IL-2 in both cohorts & & & Arm B: \\
\hline & & & & & $\begin{array}{l}\text { Immune responses } \\
5 / 6 \text { patients }(83 \%)\end{array}$ \\
\hline & & & & & PFS: 8.7 months \\
\hline & & & & & OS: 29.6 months \\
\hline
\end{tabular}

Adapted from: Kandalaft LE, Powell DJ Jr, Singh N, Coukos G. Immunotherapy for ovarian cancer: what's next? J Clin Oncol. 2011 Mar 1;29(7):925-33.

\section{Antibody therapy}

In the last fifteen years, antibody-based therapies for hematologic cancers and solid tumors have become wellestablished therapeutic strategies. Following rituximab's 1997 FDA-approval for treating chemotherapy-resistant non-Hodgkin lymphomas, 18 other molecular antibodies have gained FDA approval for use in oncologic care. Antibody therapy is a promising area of research and increasingly antibody therapies are being used in ovarian cancers.

\section{Bevacizumab}

Bevacizumab (Avastin ${ }^{\circ}$, Roche) is a humanized monoclonal antibody (mAb) that binds to all isoforms of the vascular endothelial growth factor (VEGF) receptor ligand. VEGF is a key mediator of developmental angiogenesis and has been shown to regulate the vascularization of tumors [11]. Anti-VEGF antibody therapy has proven effective in multiple cancer subtypes including metastatic colorectal cancer, glioblastoma, non-small cell lung 
cancer, and renal cancers [12]. Ovarian cancer is a promising candidate for VEGF therapy; in biopsies from ovarian tumors, VEGF gene expression correlates with a poor prognosis [13]. The results of the phase III AURELIA trial show that the addition of bevacizumab to single-agent chemotherapy leads to increased progression-free survival (PFS) and overall response rate (ORR): PFS increased from 3.4 months to 6.7 months and ORR increased from $11 \%$ to $27 \%$ [14].

\section{Catumaxomab}

Catumaxomab (Removab ${ }^{\circ}$, Fresenius Biotech $\mathrm{GmbH}$ ) is a bispecific, trifunctional antibody directed against the epithelial cell adhesion molecule (EpCAM) and the $\mathrm{T}$ cell antigen CD3. Primary, metastatic, and recurrent epithelial ovarian cancers express EpCAM at a significantly elevated level compared to normal human surface epithelium [15]. Catumaxomab uses the EpCAM and CD3 binding domains to recruit and activate immune effector cells at the tumor site [16]. Antitumor effects are exerted via two complementary pathways. First, the bispecific structure of the antibody facilitates $\mathrm{T}$ cell-mediated cytotoxicity by localizing the $\mathrm{T}$ cell and tumor tissue. Simultaneously, the retention of a functional Fc domain on the bispecific antibody allows natural killer (NK) cells to lyse tumor via antibody-dependent, cell-mediated cytotoxicity $[17,18]$. In a randomized Phase II/III study including 129 patients, puncture-free survival was significantly longer in the group receiving catumaxomab [19]. Recently, a Phase II study of catumaxomab in chemotherapy-refractory ovarian cancer patient with malignant ascites demonstrated a benefit for catumaxomab therapy: catumaxomab prolonged both the puncture free interval and the time to first therapeutic puncture as well as producing improvement in quality of life [20].

\section{Cetuximab and panitumumab}

Cetuximab (Erbitux ${ }^{\circ}, \mathrm{BMS}$ and Eli Lilly) is a chimeric, IgG1, mAb that binds to the extracellular domain of the epidermal growth factor receptor (EGFR) preventing EGFR-signaling and accelerating receptor internalization [21]. Cetuximab is routinely administered in the treatment of metastatic colorectal cancer and metastatic head and neck cancer. Up to $70 \%$ of ovarian cancer tumors and all histologic subtypes of ovarian cancer are EGFR-positive, making EGFR a promising therapeutic target in ovarian cancer [22]. In vitro, treating ovarian cancer cell lines with cetuximab inhibits cell growth, potentiates apoptosis, and impairs tumor metastasis [23].

A phase II trial of single-agent cetuximab in persistent/ recurrent ovarian or primary peritoneal carcinoma found minimal clinical benefit: nine patients had stable disease, while only one of 25 patients achieved a partial response [24]. However, a phase II trial testing cetuximab in combination with carboplatin in platinum-sensitive ovarian cancer patients reported encouraging results [25]. Out of 29 patients, 9 demonstrated an objective response and 8 had stable disease. Panitumumab (Vectibix ${ }^{\circ}$, Amgen) is another anti-EGFR antibody with strong, early-phase clinical data. A phase II study of panitumumab and the chemotherapeutic pegylated liposomal doxorubicin (PLD) in platinum-resistant ovarian cancer reported a 9\% partial response rate with stable disease in $19 \%$ of patients [26]. Out of the 32 evaluable patients, 24\% had decreased levels of CA125, a surrogate marker for ovarian tumor burden.

The limitations of single-agent cetuximab, but success of anti-EGFR therapy in combination with chemotherapeutics highlights an important preclinical reality in immunotherapy: chemotherapy and immunotherapeutics can act synergistically to enhance antitumor immunity and improve therapeutic outcomes. Chemotherapy has historically been thought to be immunosuppressive, but recent work suggests the opposite. In a variety of tumor types, patients with greater numbers of TILs have a better clinical response to cytotoxic chemotherapy [27,28]. Oxaliplatin and cisplatin, common chemotherapies for ovarian cancer, have been shown to increase dendritic cells ability to induce antigen-specific $\mathrm{T}$ cell proliferation [29]. In ID8 murine ovarian cancer cells, the combination of chemotherapeutic PLD and the immunotherapy Interleukin 18 (IL-18) resulted in enhanced tumor suppression relative to either agent as a monotherapy [30]. In EGFRexpressing xenograft models, the efficacy of cetuximab can be increased by different classes of chemotherapeutic agents, including cisplatin, doxorubicin, paclitaxel and topotecan [31,32]. In the future, strategic implementation of chemotherapy-immunotherapeutic combinations could significantly improve ovarian cancer outcomes.

\section{TAM-targeting antibodies}

Tumor-associated macrophages (TAMs) are a major stromal component in solid tumors. In the ovarian tumor microenvironment, TAMs are the most abundant subset of infiltrating immune cells [33]. However, macrophages are commonly classified into two subsets with different cytokine profiles, surface phenotypes, and functional effects on tumor growth [34]. Classical (M1-polarized) macrophages are activated by interferon $-\gamma$ (IFN- $\gamma$ ) and characterized by the production of proinflammatory and immunostimulatory cytokines (e.g. IL-6, IL-12). M1 macrophages express high levels of major histocompatibility complex (MHC) I and II and thus play a critical role in tumor antigen presentation. Through immune system stimulation and antigen presentation, M1 macrophages have a net tumoricidal effect. Alternative (M2-polarized) macrophages are activated by Th2 cytokines (e.g. IL-4, IL-10) and exert anti-inflammatory effects. Recent work reports a correlation between improved 5-year prognosis 
and elevated M1 to M2 TAM ratio in ovarian cancer patients [35].

In ovarian tumors, M2 macrophages contribute to multiple mechanisms of TAM-mediated immunosuppression. Ovarian tumor macrophages upregulate and secrete the chemokine CCL22 which promotes T regulatory cell (Treg) trafficking to the tumor. In mice bearing primary human ovarian tumors, treatment with an anti-CCL22 mAb decreased Treg migration into tumors [36]. In addition to CCL22 expression, ovarian tumor macrophages express another receptor with immunosuppressive properties, B7-H4. B7-H4 is a member of the B7 family of $\mathrm{T}$ cell-antigen presenting cell (APC) regulatory molecules. In ovarian cancer patients, $>70 \%$ of freshly isolated tumor macrophages expressed $\mathrm{B} 7-\mathrm{H} 4$ and in vitro $\mathrm{B} 7-\mathrm{H}_{4}^{+}$macrophages significantly decrease $\mathrm{T}$ cell proliferation and $\mathrm{T}$ cell activation upon TAA recognition [37]. Treatment of B7- $\mathrm{H}_{4}^{+}$TAMs with single chain fragments of antibody variable regions (scFvs) that target and block $\mathrm{B} 7-\mathrm{H} 4$, can reverse tumor immunosuppression and induce $\mathrm{T}$ cell activation [38].

While anti-CCL22 mAbs and anti-B7-H4 scFvs exert antitumor effects by modulating macrophage- $\mathrm{T}$ cell interactions, targeting the macrophage colony stimulating factor-1 receptor (CSF-1R) directly depletes immunosuppressive TAMs. Colony stimulating factor, also known as macrophage colony stimulating factor (CSF-1 or M-CSF), regulates the migration, proliferation, survival, and function of macrophages [39]. Macrophages rely on pro-growth, M-CSF signaling for survival and blocking CSF-1R provides an avenue for decreasing M2-polarized TAMs. In murine tumor models with high TAM-infiltration, the administration of an anti-CSF-1R mAb significantly reduced TAMs and simultaneously increased the ratio of cytotoxic $\mathrm{CD}^{+} \mathrm{T}$ cells to $\mathrm{CD} 4^{+} \mathrm{T}$ cells while decreasing the number of FoxP3 ${ }^{+}$Tregs [40]. In 2011, a humanized anti-CSF-1R mAb, RG7155 (Roche), entered clinical trials. The results from the ongoing Phase Ia/Ib clinical trial (NCT01494688) indicate that RG7155 treatment is well tolerated and effectively depletes TAMs [41]. Targeting macrophages is a promising therapeutic approach to ovarian cancer and encouraging early work indicates that CSF-1R blockade, anti-B7-H4 scFvs, and anti-CCL22 mAbs may generate potent antitumor responses.

\section{Immune checkpoint inhibitors}

Immune checkpoints are inhibitory pathways that downregulate activated $\mathrm{T}$ cells following antigen presentation and costimulatory signaling by APCs. By controlling the intensity and duration of the immune response, immune checkpoint signaling prevents collateral self-tissue damage. During tumorigenesis, however, cancer cells express proteins that activate immune checkpoint pathways and induce immune suppression thereby evading targeting and removal by the immune system. The clinical successes of antibodies modulating immune checkpoints continue to fuel the enthusiasm surrounding immunotherapeutic approaches to cancer treatment.

\section{CTLA-4}

The cytotoxic T-lymphocyte-associated protein 4 (CTLA-4 or CD152) plays a vital role in regulating T-cell activation [42]. Activation is triggered through antigen recognition by the T-cell receptor (TCR), but costimulatory and coinhibitory signaling dictates the magnitude of the resulting response. The cell surface molecule CD28 and its ligands CD80 (B7-1) and CD86 (B7-2) are the primary source of costimulatory signaling [43]. CD80 and CD86 are predominantly found on antigen-presenting cells like monocytes, activated B cells, and dendritic cells [44]. However, CD80 and CD86 do not exclusively induce activating signals, they are also the ligands of CTLA-4, a key negative regulator of $\mathrm{T}$ cell activation [45]. CTLA-4 directly competes with CD28 for binding to CD80 and CD86. CTLA-4 ligation results in the termination of $\mathrm{T}$ cell activation, cell cycle arrest, and $\mathrm{T}$ cell anergy. By limiting or reversing $\mathrm{T}$ cell activation, CTLA-4 serves as an important immune checkpoint that helps contain immune responses.

In the immunosuppressive tumor microenvironment, blocking CTLA-4 has the potential to directly activate $\mathrm{CD}^{+}$and $\mathrm{CD}^{+}$effector $\mathrm{T}$ cells, leading to tumor clearance. In a variety of preclinical tumor models, the administration of an antagonistic anti-CTLA-4 antibody induced tumor rejection [46]. The successes of antiCTLA-4 therapy revitalized interest in the field of immunotherapy and resulted in the 2011 FDA approval of the anti-CTLA-4 mAb ipilimumab (Yervoy ${ }^{\circ}$, BristolMyers, Squibb) [47]. The majority of clinical experience with ipilimumab has come from studies in patients with melanoma, but a Phase II study of ipilimumab monotherapy in patients with platinum-sensitive ovarian cancer is ongoing (NCT01611558).

\section{PD-1 and PD-L1 axis}

The programmed cell death protein-1 (PD1) and its ligand (PD-L1) represent a promising immune checkpoint pathway that can be targeted to reverse tumor-mediated immunosuppression. Ligation of PD1 suppresses the lytic activity of immune effector subsets [48]. In ovarian cancer, PD-L1 expression on monocytes in the ascites and blood of patients with malignant cancer correlates with poor clinical outcome [49]. Cytotoxicity assays revealed that PD-L1 overexpression on murine ovarian cancer ID8 cells inhibited cytotoxic $\mathrm{T}$ lymphocyte (CTL) degranulation and reduced CTL-mediated tumor lysis; PD-L1 blockade reversed this effect. Recently, results were presented from a phase I trial of the anti-PD1 mAb, nivolumab (BMS), in patients with platinum-resistant ovarian cancer [50]. Out 
of fifteen patients treated with nivolumab, $20 \%$ achieved partial responses and $26 \%$ had stable disease. The validation of antibodies targeting the PD-1/PD-L1 axis arrived in late 2014 when the FDA granted accelerated approval to pembrolizumab (Keytruda, Merck). Pembrolizumab is an anti-PD1 mAb that achieved an ORR of $26 \%$ in ipilimumab-refractory advanced melanoma patients [51]. mAbs targeting PD1 and PD-L1 are currently being evaluated in over 100 clinical trials and ovarian cancer remains a prioritized indication for testing.

\section{IDO}

In addition to transmembrane receptor targets, metabolic enzymes are being investigated as therapeutic strategies for reversing immunosuppression within the tumor microenvironment. Indoleamine 2,3-dioxygenase (IDO) is the leading metabolic immune regulator in clinical development.

IDO is an intracellular enzyme that catalyzes the initial and rate-limiting step of the oxidative catabolism of the amino acid tryptophan [52]. Tryptophan catabolism is believed to influence immunodynamics via two mechanisms: tryptophan depletion starves $\mathrm{T}$ lymphocytes triggering cell cycle arrest and apoptosis and the tryptophan metabolite kynurenine is toxic to lymphocytes [53,54]. Kynurenine accumulation has been linked to the selective apoptosis of T cells, monocytes, and macrophages $[55,56]$. Kynurenine can also induce the expansion of Tregs. Plasmacytoid dendritic cells (pDCs) with elevated levels of IDO can convert naive $\mathrm{CD} 4^{+} \mathrm{T}$ cells into Treg cells [57]. Inhibiting IDO in pDCs abrogates Treg generation, but adding kynurenine restores the conversion of $\mathrm{CD} 44^{+} \mathrm{CD} 25^{-} \mathrm{T}$ cells into Tregs. With mounting evidence for the immunosuppressive effects of IDO, its role in tumor immune evasion is increasingly under investigation.

The role of IDO in human cancer was first documented in 2003 by Uyttenhove et al. who reported constitutive IDO expression in most human tumors and linked elevated IDO levels to a low frequency of TILs in murine cancer models [58]. In ovarian cancers, immunohistochemical scoring of IDO expression in surgically resected tissue has demonstrated that IDO is prevalent in $\sim 56 \%$ of ovarian tumors and correlates with a reduced number of $\mathrm{CD}^{+}$TILs [59]. IDO expression also inhibits NK cell accumulation in ovarian tumors and promotes tumor angiogenesis [60]. In patients with serous-type ovarian cancer, increased synthesis of IDO is positively associated with impaired survival, but this trend was not true for other histological subtypes of OC [61]. Gene expression profiling has also found elevated IDO levels in paclitaxel-resistant ovarian cancer tissues [62].

The first IDO-targeted therapy to enter preclinical testing was 1-methyl-tryptophan (1-MT), a small molecule inhibitor of IDO. In an IDO-overexpressing ovarian cancer model, combination treatment of paclitaxel and 1-MT synergistically prolonged mouse survival relative to paclitaxel monotherapy [59]. This result supports earlier work that suggests IDO-inhibition augments the efficacy of cytotoxic chemotherapeutic agents and IDO-based combination therapy may eradicate tumors that are refractory to single-agent therapy [63]. 1-MT treatment also significantly suppressed tumor dissemination and ascites after IDO-overexpressing ovarian cancer cells were implanted into syngeneic immunocompetent mice [64].

Currently, the IDO inhibitor Indoximod ${ }^{\circ}$ (NewLink Genetics) is in five clinical trials with encouraging earlyphase clinical data [65]. In a phase I trial of Indoximod in combination with docetaxel in patients with metastatic solid tumors $18 \%$ of treated patients exhibited a partial response and $41 \%$ had stable disease. In a phase IB/II trial of indoximod in combination with AD.p53DC, a dendritic cell cancer vaccine, 9\% of patients achieved stable disease with initial treatment. Following combination therapy, 11 patients showed tumor progression and then received gemcitabine-based chemotherapy; $54 \%$ of these patients achieved an objective response. A secondgeneration IDO-inhibitor, NLG919 (NewLink Genetics), entered clinical trials in late 2013 (NCT02048709). Both inhibitors are orally bioavailable and are being tested in patients with recurrent solid tumors.

In addition to the IDO inhibitors developed by NewLink Genetics, INCB024360 (Incyte Corp.), an IDO1 inhibitor, has entered clinical testing. In preclinical data, INCB024360 was shown to significantly inhibit tumor growth and to induce $\mathrm{T}$ and NK cell proliferation and IFN- $\gamma$ production [66]. In the Phase I safety and tolerability trial, at doses above $300 \mathrm{mg}$ twice a day, $90 \%$ inhibition of IDO activity was observed, with pneumonitis and fatigue reported as the only dose-limiting toxicities [67]. A Phase II trial of INCB024360 monotherapy versus tamoxifen in patients with epithelial ovarian cancer is ongoing (NCT01685255). As IDO inhibitors enter the clinic, it will be important to monitor the immunologic effects of global IDO inhibition with special attention focused on the onset of autoimmune dysfunction. In the MRL-lpr mouse model of spontaneous lupus disease, 1-MT treatment accelerates lupus onset [68].

\section{Vaccine strategies}

Therapeutic cancer vaccines have been an area of research interest since the 1920s, when injections of lymph node extracts were used to treat Hodgkin's lymphoma. The promise of vaccine strategies is the potential to "teach" individual patients' immune systems to recognize, target, and eradicate tumor cells in an approach that employs both adaptive and innate immunity. Vaccines aim to provoke a tumor-specific immune response by increasing TAA presentation by APCs thus generating tumor-antigen 
specific cytotoxic $\mathrm{T}$ lymphocytes. Unlike chemotherapy, surgery, radiotherapy, or antibody therapy, an effective vaccine-induced immune response could establish a state of immunological memory that persists after tumor clearance and indefinitely suppresses tumor regrowth. In recent decades, multiple approaches to therapeutic cancer vaccines have been developed and dendritic cell vaccines have emerged as efficacious in ovarian cancer.

\section{Ex vivo $\mathrm{DC}$ vaccines}

Dendritic cells (DCs), the most potent class of APCs, are responsible for processing cancer antigens from tumor cells and presenting peptide fragments to naive T cells, B cells, and NK cells. DC vaccines attempt to enhance DC uptake and presentation of TAAs, galvanizing an antitumor response. In ovarian cancer, a promising TAA for DC vaccines is mucin 1 (MUC-1). MUC-1 is a heavily glycosylated, type 1 transmembrane protein that is overexpressed in a large number of cancers including colorectal, pancreatic, and ovarian [69]. While multiple MUC-1 vaccines are now in development, $\mathrm{CVac}^{\circ}$ (Prima BioMed) is the leading candidate for treatment of ovarian cancer. CVac is produced by culturing isolated DCs ex vivo with MUC-1. In the CAN-003 Phase II study, 63 epithelial ovarian cancer patients in complete remission received CVac. In the patients who had achieved a remission after second-line therapy, PFS and OS were increased [70].

\section{In vivo $\mathrm{DC}$ vaccines}

Ex vivo $\mathrm{DC}$ vaccines require isolating and stimulating DCs on a patient-specific basis and are thus costly, labor-intensive, and mostly limited to large, academic medical centers. An attractive alternative is to use an "off-the-shelf" therapeutic that is not patient-specific and stimulates DCs to uptake TAAs in vivo. One example of an early, preclinical success with this approach in ovarian cancer is the administration of a vaccine based on the MSLN-Hsp70 fusion protein [71]. The MSLN-Hsp70 protein combines a scFv to mesothelin (MSLN), an antigen overexpressed in pancreatic and ovarian tumors, and a heat shock protein from Mycobacterium tuberculosis (Hsp70). In this system, the dendritic cells are activated by the tuberculosis Hsp70 and, because the fusion protein localizes DC activation to MSLN-expressing cells, immediately recognize the tumor antigen. Administration of the bifunctional fusion protein in mouse models of ovarian cancer significantly enhanced survival and slowed tumor growth while augmenting tumor-specific $\mathrm{CD}^{+} \mathrm{T}$ cell responses.

\section{Whole tumor DC-based vaccines}

A potential avenue for improving the efficacy of DC vaccines is the inclusion of multiple tumor antigens during DC priming. When immunotherapeutic intervention is limited to a single target antigen, there is the possibility of tumor escape. Tumor escape occurs when the tumor mutates to downregulate the immunogenic antigen and thus evades immune system surveillance and continues to proliferate. By preparing vaccines from whole tumor cells, the immune system can be trained to recognize a broad range of TAAs. Whole-tumor preparations also eliminate the need for researchers to identify an optimal antigen target; unknown tumor antigens may drive or contribute to the cellular immune response. Recent work utilized a lysate of tumor cells to demonstrate the effectiveness of whole tumor DC-based vaccination against ovarian cancer in both a preclinical and clinical setting [72]. In the clinic, out of the five patients who received the DC vaccine, two had PFS of 24 months or more (NCT01132014).

\section{Peptide vaccines}

Peptide vaccines rely primarily on the immunogenicity of the injected peptides to stimulate an immune response. In the cancer setting, the peptides chosen for the vaccine are TAAs. Recently, overlapping long peptides (OLP) from NY-ESO-1 were used as a peptide vaccine in combination with two different adjuvant preparations: Montanide and Poly-ICLC [73]. After OLP vaccination alone, NY-ESO-1specific $\mathrm{CD}^{+} \mathrm{T}$ cells and NY-ESO-1-specific antibody responses were undetectable, but after vaccination with OLP and administration of both Montanide and PolyICLC, 91\% of patients demonstrated both a NY-ESO-1specific $\mathrm{CD}^{+} \mathrm{T}$ cells and a NY-ESO-1-specific antibody response. Additional targets for peptide vaccine strategies in ovarian cancer include p53, Her-2/neu, and CA125 [74-76]. While peptide vaccines have proven effective at eliciting TAA-specific immune responses, combination with complementary immunotherapeutic modalities may be necessary to generate potent antitumor immunity.

\section{Recombinant viral vaccines}

Recombinant viral vaccines utilize genetically modified viruses as vectors for introducing TAA-encoding DNA into cells within the body [77]. Viruses are an attractive antigen-delivery system because most viruses elicit an immune response; viral immunogenicity induces immune cell trafficking to the injection site, where professional APCs, like DCs, encounter the newly introduced TAAs. APCs then return to lymph nodes with the digested and expressed TAA and induce a tumor-specific humoral or cellular immune response. The discovery of TAAs for ovarian tumors has spurred the development of therapeutic recombinant viral vaccines for patients with ovarian cancer.

The cancer testis antigen NY-ESO-1 is a well-documented target for immunotherapy of ovarian cancer and has been the focus of multiple cancer vaccine studies [78-80]. 
Recently, NY-ESO-1-recombinant vaccinia and fowlpox vectors were used in parallel Phase II clinical trials, producing encouraging immunologic data [81]. Induction of a NY-ESO-1-specific antibody response was observed in $42 \%$ of patients who were seronegative at the baseline assessment. $\mathrm{CD}^{+} \mathrm{T}$ cell responses were induced in $32 \%$ of patients (14\% had a preexisting response), while $\mathrm{CD} 4^{+} \mathrm{T}$ cell responses were induced in $22 \%$ of patients ( $68 \%$ had a preexisting response). In the ovarian cancer patients, the median PFS was 21 months and the median overall survival (OS) was 48 months. Poxviral vectors are also the basis for the PANVAC vaccine platform, which is actively being tested in ovarian cancer patients (NCT00088413). PANVAC is a cancer vaccine therapy that contains transgenes for the TAAs MUC-1 and carcinoembryonic antigen (CEA) as well as transgenes for three human T cell costimulatory molecules, collectively known as TRICOM (B7-1, intracellular adhesion molecule-1 and leukocyte function-associated antigen-3) [82]. In a pilot study of PANVAC in 14 ovarian cancer patients, median time to progression was 2 months and median OS was 15.0 months [83].

The convenience, low toxicity, and potential therapeutic activity of vaccine strategies make them an irresistible target of future immunotherapeutic research. As optimal vaccine platforms, antigen targets, and adjuvant conditions are identified, vaccines will become an increasingly valuable therapeutic option for treating ovarian cancer.

\section{Adoptive cell therapy}

Adoptive Cell Therapy (ACT) is an immunotherapeutic technique that uses autologous or allogeneic antitumor lymphocytes to induce cancer regression. In autologous ACT, lymphocytes are isolated via apheresis, cultured, and assayed for tumor recognition. Highly reactive cultures are expanded and reinfused into the cancer patient. Lymphodepleting chemotherapy preceding infusion eliminates immunosuppressive cells and supports the in vivo survival and expansion of tumor-specific lymphocytes. First described in 1988, ACT initially demonstrated strong responses in melanoma, but has since been tested in other tumor types including ovarian cancers [84,85]. A 1995 trial comparing the effect of adoptive cell therapy on advanced-stage epithelial ovarian cancer found the 3-year overall survival rates between the ACT group and the controls, who did not receive ACT, to be $100 \%$ and $67.5 \%$, respectively [86]. However, ACT is limited by the availability of tumor-specific lymphocytes. Recent advances in cellular genetic engineering have addressed this limitation. Using retro-viral vectors, antigen-specific $\mathrm{T}$ cell receptors are transduced into normal peripheral blood lymphocytes (PBLs) converting them into cells that accurately target and lyse tumor [87]. The antigen-specific $\mathrm{T}$ cell receptors, or chimeric antigen receptors (CARs), are composed of scFvs specific to the tumor antigen of interest and a $T$ cell signaling domain capable of inducing activation.

In the ID8 mouse model of ovarian cancer, T cells transduced to express an NKG2D-based CAR demonstrated an endogenous antitumor immunity and long-term, tumorfree survival [88]. Surviving mice developed T cell memory responses that were protective: $90 \%$ of mice rejected the rechallenge with ID8 tumor cells. In a separate study, treatment with chimeric-NKG2D $\mathrm{T}$ cells also increased the number of host $\mathrm{CD}_{4}^{+}$and $\mathrm{CD}^{+} \mathrm{T}$ cells at the tumor site and increased the number of antigen-specific host $\mathrm{CD} 4^{+} \mathrm{T}$ cells in the tumor and draining lymph nodes [89]. With encouraging initial results of CAR-based therapy in ovarian models, multiple ovarian-specific tumor antigens are being used in CAR development and ACT strategies are moving towards the clinic [90].

\section{Combinatorial immunotherapy}

While single-agent immunotherapies have produced promising clinical responses, unleashing the maximal antitumor immune response is likely to require combinatorial therapeutic strategies [91]. As illustrated above, for a tumor to uncontrollably proliferate and evade detection by the immune system, multiple "tumor escape mechanisms" must act concertedly [92]. By combining immunotherapies, different stages of tumor escape can be targeted, creating the possibility of synergistic and additive effects between agents [93]. Despite the novelty of immunotherapeutic treatments in ovarian cancer, combination strategies are an area of intense research and combinatorial trials have entered the clinic.

The initial combination immunotherapies for ovarian cancer patients were based on immune checkpoint blockade strategies. In the ID8-VEGF model of ovarian carcinoma, researchers observed that up to half of TILs were double positive for both CTLA-4 and PD- 1 and displayed a decreased proliferation capacity and inability to produce effector cytokines [94]. Co-administration of anti-PD-1 antibodies and anti-CTLA-4 antibodies reversed the TIL dysfunction and induced tumor regression in $50 \%$ of the mice relative to $25 \%$ with either agent as a monotherapy. The addition of the GM-CSF gene vaccine, GVAX, to the therapeutic regimen further increased tumor rejection to $75 \%$ in the ID8-VEGF mice. The combination of antiCTLA-4 and GVAX has also been tested in eleven-patients with metastatic ovarian carcinoma [95]. Three patients achieved stable disease as measured by CA-125 levels and one patient achieved an objective response by radiographic criteria and maintained disease control over four years with regular infusions of anti-CTLA-4 antibody. In addition to preclinical research, the recent successes of trials evaluating nivolumab have spurred nivolumab-based combinations, including a Phase I/II trial evaluating nivolumab 
and the IDO inhibitor INCB24360 in patients with ovarian neoplasms (NCT02327078).

Combination immunotherapy trials have also expanded to include vaccine strategies, mAb therapy, and $\mathrm{ACT}$. In a trial for patients with recurrent ovarian cancer, a DC-based autologous whole-tumor lysate vaccine was tested in combination with the anti-angiogenic mAb bevacizumab (NCT01312376). Of the six patients who participated, four patients demonstrated a clinical benefit and an increase in tumor-reactive $\mathrm{T}$ cells following vaccination; tumor reactivity was quantified by measuring IFN- $\gamma$ secretion [96]. From these four patients, three patients with residual measurable disease advanced to a study where they received adoptive transfer of autologous vaccine-primed, CD3/CD28-co-stimulated T cells (NCT00603460). By the end of study, one patient had achieved a complete response, one patient had a partial response, and one patient had progressive disease [96].

In the near future, the number of combination immunotherapy studies targeting ovarian cancer patients will dramatically increase. However, the application of multiple immunotherapies simultaneously requires careful considerations. Primarily, with combination treatments there is a potential for overlapping toxicities and elevated risk of sequela due to immune system disinhibition. Effective adverse-event management will be a crucial element of successful combination immunotherapy. Secondly, there is a need to optimize the timing of agent administration; in some situations, sequential administration may prove more advantageous than concurrent administration. If immune-related toxicities can be controlled and ideal dosing determined, combinatorial immunotherapy may dramatically improve the clinical outcomes of ovarian cancer patients.

\section{Conclusions}

Early clinical successes have validated immunotherapeutic treatment strategies and immunotherapies hold immense potential to improve outcomes for patients with ovarian cancer. In future research, it will be important to identify the dominant immunosuppressive pathways within ovarian tumors. A better understanding of the relevant immuno-oncologic pathways and their corresponding biomarkers will allow patients to be optimally matched with therapies. In conjunction with biomarker research, combination strategies should continue to be explored. Combination approaches are uniquely appealing because different classes of immunotherapies target potentially synergistic stages of tumor immunity. Within the tumor microenvironment, immunotherapies may increase antigen release or antigen presentation, induce cytotoxicity via effector immune subsets, or remove immunosuppression. Identifying the optimal combination of drugs to provoke a concerted antitumor response will translate to substantial improvements in long-term clinical benefit.

\section{Competing interests}

All authors declare that they have no competing interests.

\section{Author's Contribution}

CC performed the literature search, drafted and edited all versions of the manuscript, and incorporated all edits from OD, JS, and HK. OD, JS, and HK supervised preparation of the manuscript, contributed ideas and publications to be used in drafting the manuscript, and read and edited all drafts of the manuscript. All authors read and approved the final manuscript.

\section{Acknowledgments}

We would like to thank OvaCure and The Anticancer Fund for their support in the manuscript preparation and review.

\section{Author details}

'Department of Medicine, Division of Oncology, Stanford University School of Medicine, Stanford, CA, USA. ${ }^{2}$ Stanford Women's Cancer Center, Division of Gynecologic Oncology, Department of Obstetrics and Gynecology, Stanford University School of Medicine, Stanford, CA 94305, USA.

Received: 24 November 2014 Accepted: 16 February 2015 Published online: 24 March 2015

\section{References}

1. Ferlay J, Soerjomataram I, Ervik M, Dikshit R, Eser S, Mathers C, et al. GLOBOCAN 2012 v1. 0, Cancer Incidence and Mortality Worldwide: IARC CancerBase No. 11. Lyon, France: International Agency for Research on Cancer; 2013. Last accessed April 2014.

2. Jayson GC, Kohn EC, Kitchener HC, Ledermann JA. Ovarian cancer. Lancet. 2014;384:1376-88.

3. Goff BA, Mandel L, Muntz HG, Melancon $\mathrm{CH}$. Ovarian carcinoma diagnosis. Cancer. 2000;89:2068-75.

4. Herzog TJ. The current treatment of recurrent ovarian cancer. Current oncology reports. 2006;8:448-54.

5. Baldwin LA, Huang B, Miller RW, Tucker T, Goodrich ST, Podzielinski I, et al. Ten-year relative survival for epithelial ovarian cancer. Obstetrics and gynecology. 2012;120:612-8.

6. Zhang L, Conejo-Garcia JR, Katsaros D, Gimotty PA, Massobrio M, Regnani G, et al. Intratumoral T cells, recurrence, and survival in epithelial ovarian cancer. NEJM. 2003;348:203-13.

7. Hwang WT, Adams SF, Tahirovic E, Hagemann IS, Coukos G. Prognostic significance of tumor-infiltrating $T$ cells in ovarian cancer: a meta-analysis. Gynecologic oncology. 2012;124:192-8.

8. Chu CS, Kim SH, June CH, Coukos G. Immunotherapy opportunities in ovarian cancer. Expert review of anticancer therapy. 2008;8:243-57.

9. Walters CL, Arend RC, Armstrong DK, Naumann RW, Alvarez RD. Folate and folate receptor alpha antagonists mechanism of action in ovarian cancer. Gynecologic oncology. 2013;131:493-8.

10. Yakirevich E, Sabo E, Lavie O, Mazareb S, Spagnoli GC, Resnick MB. Expression of the MAGE-A4 and NY-ESO-1 cancer-testis antigens in serous ovarian neoplasms. Clinical cancer research. 2003;9:6453-60.

11. Ferrara N, Gerber HP, LeCouter J. The biology of VEGF and its receptors. Nature medicine. 2003;9:669-76.

12. Hsu JY, Wakelee HA. Monoclonal antibodies targeting vascular endothelial growth factor. BioDrugs. 2009;23:289-304.

13. Hata K, Watanabe $Y$, Nakai H, Hata T, Hoshiai H. Expression of the vascular endothelial growth factor (VEGF) gene in epithelial ovarian cancer: an approach to anti-VEGF therapy. Anticancer research. 2011;31:731-7.

14. Pujade-Lauraine E, Hilpert F, Weber B, Reuss A, Poveda A, Kristensen G, et al. Bevacizumab combined with chemotherapy for platinum-resistant recurrent ovarian cancer: the AURELIA open-label randomized phase III trial. J Clin Oncol. 2014;32:1302-8.

15. Bellone S, Siegel ER, Cocco E, Cargnelutti M, Silasi DA, Azodi M, Schwartz PE, Rutherford TJ, Pecorelli S, Santin AD: Overexpression of epithelial cell adhesion molecule in primary, metastatic, and recurrent/chemotherapy-resistant epithelial ovarian cancer. International journal of gynecological cancer 2009;19:860-866. 
16. Linke R, Klein A, Seimetz D. Catumaxomab: clinical development and future directions. mAbs. 2010;2:129-36.

17. Kohrt HE, Houot R, Marabelle A, Cho HJ, Osman K, Goldstein M, et al. Combination strategies to enhance antitumor ADCC. Immunotherapy. 2012;4:511-27.

18. Chester C, Marabelle A, Houot R, Kohrt HE. Dual antibody therapy to harness the innate anti-tumor immune response to enhance antibody targeting of tumors. Curr Opin Immunol. 2015;33C:1-8.

19. Heiss MM, Murawa P, Koralewski P, Kutarska E, Kolesnik OO, Ivanchenko W, et al. The trifunctional antibody catumaxomab for the treatment of malignant ascites due to epithelial cancer: Results of a prospective randomized phase I//II trial. International journal of cancer. 2010;127:2209-21.

20. Berek JS, Edwards RP, Parker LP, DeMars LR, Herzog TJ, Lentz SS, et al. Catumaxomab for the treatment of malignant ascites in patients with chemotherapy-refractory ovarian cancer: a phase II study. Int J Gynecol Cancer. 2014;24:1583-9.

21. Patel D, Lahiji A, Patel S, Franklin M, Jimenez $X$, Hicklin DJ, et al. Monoclonal antibody cetuximab binds to and down-regulates constitutively activated epidermal growth factor receptor vlll on the cell surface. Anticancer research. 2007;27:3355-66.

22. Lin CK, Chao TK, Yu CP, Yu MH, Jin JS. The expression of six biomarkers in the four most common ovarian cancers: correlation with clinicopathological parameters. APMIS. 2009;117:162-75.

23. Mendelsohn J, Baselga J. Status of epidermal growth factor receptor antagonists in the biology and treatment of cancer. Journal of clinical oncology. 2003;21:2787-99

24. Schilder RJ, Pathak HB, Lokshin AE, Holloway RW, Alvarez RD, Aghajanian C, et al. Phase II trial of single agent cetuximab in patients with persistent or recurrent epithelial ovarian or primary peritoneal carcinoma with the potential for dose escalation to rash. Gynecologic oncology. 2009;113:21-7.

25. Secord AA, Blessing JA, Armstrong DK, Rodgers WH, Miner Z, Barnes MN, et al. Phase II trial of cetuximab and carboplatin in relapsed platinum-sensitive ovarian cancer and evaluation of epidermal growth factor receptor expression: A Gynecologic Oncology Group study. Gynecologic oncology. 2008;108:493-9.

26. Steffensen KD, Waldstrom M, Pallisgard N, Lund B, Bergfeldt K, Wihl J, et al. Panitumumab and pegylated liposomal doxorubicin in platinum-resistant epithelial ovarian cancer with KRAS wild-type: the PaLiDo study, a phase II nonrandomized multicenter study. International journal of gynecological cancer. 2013;23:73-80.

27. Denkert C, Loibl S, Noske A, Roller M, Muller BM, Komor M, et al. Tumor-associated lymphocytes as an independent predictor of response to neoadjuvant chemotherapy in breast cancer. Journal of clinical oncology. 2010;28:105-13.

28. Halama N, Michel S, Kloor M, Zoernig I, Benner A, Spille A, et al. Localization and density of immune cells in the invasive margin of human colorectal cancer liver metastases are prognostic for response to chemotherapy. Cancer research. 2011;71:5670-7.

29. Hato SV, De V, Lesterhuis WJ. STATing the importance of immune modulation by platinum chemotherapeutics. Oncoimmunology. 2012;1:234-6.

30. Alagkiozidis I, Facciabene A, Carpenito C, Benencia F, Jonak Z, Adams S, et al. Increased immunogenicity of surviving tumor cells enables cooperation between liposomal doxorubicin and IL-18. Journal of translational medicine. 2009;7:104.

31. Fan Z, Baselga J, Masui H, Mendelsohn J. Antitumor effect of anti-epidermal growth factor receptor monoclonal antibodies plus cisdiamminedichloroplatinum on well established A431 cell xenografts. Cancer Res. 1993:53:4637-42.

32. Ciardiello F, Bianco R, Damiano V, De Lorenzo S, Pepe S, De Placido S, et al. Antitumor activity of sequential treatment with topotecan and anti-epidermal growth factor receptor monoclonal antibody C225. Clin Cancer Res. 1999:5:909-16.

33. Wang X, Deavers M, Patenia R, Bassett RL, Mueller P, Ma Q, et al. Monocyte/ macrophage and T-cell infiltrates in peritoneum of patients with ovarian cancer or benign pelvic disease. Journal of translational medicine. 2006:4:30.

34. Mantovani A, Sozzani S, Locati M, Allavena P, Sica A. Macrophage polarization: tumor-associated macrophages as a paradigm for polarized M2 mononuclear phagocytes. Trends in immunology. 2002;23:549-55.

35. Zhang S, Yu M, Deng H, Shen G, Wei Y. Polyclonal rabbit anti-human ovarian cancer globulins inhibit tumor growth through apoptosis involving the caspase signaling. Scientific reports. 2014;4:4984.
36. Curiel TJ, Coukos G, Zou L, Alvarez X, Cheng P, Mottram P, et al. Specific recruitment of regulatory $T$ cells in ovarian carcinoma fosters immune privilege and predicts reduced survival. Nature medicine. 2004;10:942-9.

37. Kryczek I, Zou L, Rodriguez P, Zhu G, Wei S, Mottram P, et al. B7-H4 expression identifies a novel suppressive macrophage population in human ovarian carcinoma. The Journal of experimental medicine. 2006;203:871-81.

38. Dangaj D, Lanitis E, Zhao A, Joshi S, Cheng Y, Sandaltzopoulos R, et al. Novel recombinant human b7-h4 antibodies overcome tumoral immune escape to potentiate T-cell antitumor responses. Cancer research. 2013;73:4820-9.

39. Hume DA, MacDonald KP. Therapeutic applications of macrophage colony-stimulating factor-1 (CSF-1) and antagonists of CSF-1 receptor (CSF-1R) signaling. Blood. 2012;119:1810-20.

40. Ries CH, Cannarile MA, Hoves S, Benz J, Wartha K, Runza V, et al. Targeting tumor-associated macrophages with anti-CSF-1R antibody reveals a strategy for cancer therapy. Cancer cell. 2014;25:846-59.

41. Cassier PA. Phase 1 study of RG7155, a novel anti-CSF1R antibody, in patients with locally advanced pigmented villonodular synovitis (PVNS), ASCO Annual Meeting. 2014. Abstract \#10504 2014: http://meetinglibrary. asco.org/content/131522-144.

42. Korman AJ, Peggs KS, Allison JP. Checkpoint blockade in cancer immunotherapy. Adv Immunol. 2006:90:297-339.

43. Hathcock KS, Laszlo G, Pucillo C, Linsley P, Hodes RJ. Comparative analysis of B7-1 and B7-2 costimulatory ligands: expression and function. J Exp Med. 1994;180:631-40.

44. Azuma M, Ito D, Yagita H, Okumura K, Phillips JH, Lanier LL, et al. B70 antigen is a second ligand for CTLA-4 and CD28. Nature. 1993;366:76-9.

45. Chambers CA, Kuhns MS, Egen JG, Allison JP. CTLA-4-mediated inhibition in regulation of $T$ cell responses: mechanisms and manipulation in tumor immunotherapy. Annu Rev Immunol. 2001;19:565-94.

46. Egen JG, Kuhns MS, Allison JP. CTLA-4: new insights into its biological function and use in tumor immunotherapy. Nature Immunology. 2002;3:611-8.

47. Lipson EJ, Drake CG. Ipilimumab: an anti-CTLA-4 antibody for metastatic melanoma. Clinical Cancer Research. 2011;17:6958-62.

48. Terme M, Ullrich E, Aymeric L, Meinhardt K, Desbois M, Delahaye N, et al. IL-18 induces PD-1-dependent immunosuppression in cancer. Cancer research. 2011;71:5393-9.

49. Maine CJ, Aziz NH, Chatterjee J, Hayford C, Brewig N, Whilding L, et al. Programmed death ligand-1 over-expression correlates with malignancy and contributes to immune regulation in ovarian cancer. Cll. 2014;63:215-24.

50. Hamanishi J. Efficacy and safety of anti-PD-1 antibody (Nivolumab: BMS-936558, ONO-4538) in patients with platinum-resistant ovarian cancer, ASCO Annual Meeting. 2014. Abstract\# 5511 2014: http://meetinglibrary. asco.org/content/130814-144.

51. Robert C, Ribas A, Wolchok JD, Hodi FS, Hamid O, Kefford R, et al. Anti-programmed-death-receptor-1 treatment with pembrolizumab in ipilimumab-refractory advanced melanoma: a randomised dose-comparison cohort of a phase 1 trial. Lancet. 2014;384:1109-17.

52. Takikawa O. Biochemical and medical aspects of the indoleamine 2,3-dioxygenase-initiated I-tryptophan metabolism. Biochemical and biophysical research communications. 2005;338:12-9.

53. Frumento G, Rotondo R, Tonetti M, Damonte G, Benatti U, Ferrara GB. Tryptophan-derived catabolites are responsible for inhibition of $\mathrm{T}$ and natural killer cell proliferation induced by indoleamine 2,3-dioxygenase. The Journal of experimental medicine. 2002;196:459-68.

54. Munn DH, Shafizadeh E, Attwood JT, Bondarev I, Pashine A, Mellor AL. Inhibition of T cell proliferation by macrophage tryptophan catabolism The Journal of experimental medicine. 1999;189:1363-72.

55. Fallarino F, Grohmann U, Vacca C, Orabona C, Spreca A, Fioretti MC, et al. $T$ cell apoptosis by kynurenines. Advances in experimental medicine and biology. 2003;527:183-90.

56. Morita T, Saito K, Takemura M, Maekawa N, Fujigaki S, Fujii H, et al. L-tryptophan-kynurenine pathway metabolite 3-hydroxyanthranilic acid induces apoptosis in macrophage-derived cells under pathophysiological conditions. Adv Exp Med Biol. 1999;467:559-63.

57. Chen W, Liang X, Peterson AJ, Munn DH, Blazar BR. The indoleamine 2,3-dioxygenase pathway is essential for human plasmacytoid dendritic cell-induced adaptive $T$ regulatory cell generation. Journal of immunology. 2008;181:5396-404.

58. Uyttenhove C, Pilotte L, Theate I, Stroobant V, Colau D, Parmentier N, et al. Evidence for a tumoral immune resistance mechanism based on tryptophan. Nature medicine. 2003;9:1269-74. 
59. Inaba T, Ino K, Kajiyama H, Yamamoto E, Shibata K, Nawa A, et al. Role of the immunosuppressive enzyme indoleamine 2,3-dioxygenase in the progression of ovarian carcinoma. Gynecologic oncology. 2009;115:185-92.

60. Nonaka H, Saga Y, Fujiwara H, Akimoto H, Yamada A, Kagawa S, et al. Indoleamine 2,3-dioxygenase promotes peritoneal dissemination of ovarian cancer. International journal of oncology. 2011;38:113-20.

61. Takao M, Okamoto A, Nikaido T, Urashima M, Takakura S, Saito M, et al. Increased synthesis of indoleamine-2,3-dioxygenase protein is positively associated with impaired survival in patients with serous-type, but not with other types of, ovarian cancer. Oncology reports. 2007;17:1333-9.

62. Okamoto A, Nikaido T, Ochiai K, Takakura S, Saito M, Aoki Y, et al. Indoleamine 2,3-dioxygenase serves as a marker of poor prognosis in gene expression profiles of serous ovarian cancer cells. Clinical cancer research. 2005:11:6030-9.

63. Muller AJ, DuHadaway JB, Donover PS, Sutanto-Ward E, Prendergast GC. Inhibition of indoleamine 2,3-dioxygenase, an immunoregulatory target of the cancer suppression gene Bin 1, potentiates cancer chemotherapy. Nature medicine. 2005;11:312-9.

64. Tanizaki Y, Kobayashi A, Toujima S, Shiro M, Mizoguchi M, Mabuchi Y, et al. Indoleamine 2,3-dioxygenase promotes peritoneal metastasis of ovarian cancer by inducing an immunosuppressive environment. Cancer science. 2014; 105:966-73.

65. Liu X, Shin N, Koblish HK, Yang G, Wang Q, Wang K, et al. Selective inhibition of IDO1 effectively regulates mediators of antitumor immunity. Blood. 2010;115:3520-30.

66. Jackson R, Dees EC, Kauh JS, et al. A phase I study of indoximod in combination with docetaxel in metastatic solid tumors, ASCO Annual Meeting. 2013. Abstract \#3026.

67. Newton RC, Scherle PA, Bowman K, Liu X, Beatty GL, O'Dwyer PJ, et al. Pharmacodynamic assessment of INCB024360, an inhibitor of indoleamine 2,3-dioxygenase 1 (IDO1) in advancer cancer patients, ASCO Annual Meeting. 2012. Abstract \#2500. http://meetinglibrary.asco.org/content/96898-114.

68. Ravishankar B, Liu H, Shinde R, Chandler P, Baban B, Tanaka M, et al. Tolerance to apoptotic cells is regulated by indoleamine 2,3-dioxygenase. PNAS. 2012;109:3909-14.

69. Lakshminarayanan $\mathrm{V}$, Thompson P, Wolfert MA, Buskas T, Bradley JM, Pathangey LB, et al. Immune recognition of tumor-associated mucin MUC1 is achieved by a fully synthetic aberrantly glycosylated MUC1 tripartite vaccine. PNAS. 2012;109:261-6.

70. Gray HJ, Gargosky SE. Progression-free survival in ovarian cancer patients in second remission with mucin-1 autologous dendritic cell therapy. Abstract \#5504. Oral Presentation, ASCO Annual Meeting. 2014.

71. Yuan J, Kashiwagi S, Reeves P, Nezivar J, Yang Y, Arrifin NH, et al. A novel mycobacterial Hsp70-containing fusion protein targeting mesothelin augments antitumor immunity and prolongs survival in murine models of ovarian cancer and mesothelioma. J Hematol Oncol. 2014;7:15.

72. Chiang CL, Kandalaft LE, Tanyi J, Hagemann AR, Motz GT, Svoronos N, et al. A dendritic cell vaccine pulsed with autologous hypochlorous acid-oxidized ovarian cancer lysate primes effective broad antitumor immunity: from bench to bedside. Clinical cancer research. 2013;19:4801-15.

73. Sabbatini P, Tsuji T, Ferran L, Ritter E, Sedrak C, Tuballes K, et al. Phase I tria of overlapping long peptides from a tumor self-antigen and poly-ICLC shows rapid induction of integrated immune response in ovarian cancer patients. Clinical Cancer Research. 2012;18:6497-508.

74. Leffers N, Lambeck AJ, Gooden MJ, Hoogeboom BN, Wolf R, Hamming IE, et al. Immunization with a P53 synthetic long peptide vaccine induces P53-specific immune responses in ovarian cancer patients, a phase II trial. Int J Cancer. 2009;125:2104-13.

75. Chianese-Bullock KA, Irvin Jr WP, Petroni GR, Murphy C, Smolkin M, Olson WC, et al. A multipeptide vaccine is safe and elicits T-cell responses in participants with advanced stage ovarian cancer. J Immunother. 2008;31:420-30.

76. Reinartz S, Köhler S, Schlebusch H, Krista K, Giffels P, Renke K, et al. Vaccination of patients with advanced ovarian carcinoma with the anti-idiotype ACA125: immunological response and survival (phase lb/Il). Clinical Cancer Research. 2004;10:1580-7.

77. Larocca C, Schlom J. Viral vector-based therapeutic cancer vaccines. Cancer J. 2011;17:359-71.

78. Odunsi K, Jungbluth AA, Stockert E, Qian F, Gnjatic S, Tammela J, et al. NY-ESO-1 and LAGE-1 cancer-testis antigens are potential targets for immunotherapy in epithelial ovarian cancer. Cancer Research. 2003:63:6076-83.
79. Jäger E, Karbach J, Gnjatic S, Neumann A, Bender A, Valmori D, et al. Recombinant vaccinia/fowlpox NY-ESO-1 vaccines induce both humoral and cellular NY-ESO-1-specific immune responses in cancer patients. Proc Natl Acad Sci. 2006;103:14453-8.

80. Valmori D, Souleimanian NE, Tosello V, Bhardwaj N, Adams S, O'Neill D, et al. Vaccination with NY-ESO-1 protein and CpG in Montanide induces integrated antibody/Th1 responses and CD8 T cells through cross-priming. Proc Natl Acad Sci. 2007;104:8947-52.

81. Odunsi K, Matsuzaki J, Karbach J, Neumann A, Mhawech-Fauceglia P, Miller A, et al. Efficacy of vaccination with recombinant vaccinia and fowlpox vectors expressing NY-ESO-1 antigen in ovarian cancer and melanoma patients. Proc Natl Acad Sci. 2012;109:5797-802.

82. Madan RA, Arlen PM, Gulley JL. PANVAC-VF: poxviral-based vaccine therapy targeting CEA and MUC1 in carcinoma. Expert Opin Biol Ther. 2007;7:543-54.

83. Mohebtash M, Tsang KY, Madan RA, Huen NY, Poole DJ, Jochems C, et al. A pilot study of MUC-1/CEA/TRICOM poxviral-based vaccine in patients with metastatic breast and ovarian cancer. Clinical Cancer Research. 2011;17:7164-73.

84. Rosenberg SA, Packard BS, Aebersold PM, Solomon D, Topalian SL, Toy ST, et al. Use of tumor-infiltrating lymphocytes and interleukin-2 in the immunotherapy of patients with metastatic melanoma. NEJM. 1988;319:1676-80.

85. Aoki Y, Takakuwa K, Kodama S, Tanaka K, Takahashi M, Tokunaga A, et al. Use of adoptive transfer of tumor-infiltrating lymphocytes alone or in combination with cisplatin-containing chemotherapy in patients with epithelial ovarian cancer. Cancer research. 1991;51:1934-9.

86. Fujita K, Ikarashi H, Takakuwa K, Kodama S, Tokunaga A, Takahashi T, et al. Prolonged disease-free period in patients with advanced epithelial ovarian cancer after adoptive transfer of tumor-infiltrating lymphocytes. Clin Cancer Res. 1995;1:501-7.

87. Morgan RA, Dudley ME, Wunderlich JR, Hughes MS, Yang JC, Sherry RM, et al. Cancer regression in patients after transfer of genetically engineered lymphocytes. Science. 2006;314:126-9.

88. Barber A, Zhang T, Sentman CL. Immunotherapy with chimeric NKG2D receptors leads to long-term tumor-free survival and development of host antitumor immunity in murine ovarian cancer. Journal of immunology. 2008;180:72-8.

89. Spear P, Barber A, Sentman CL. Collaboration of chimeric antigen receptor (CAR)-expressing T cells and host T cells for optimal elimination of established ovarian tumors. Oncoimmunology. 2013;2:e23564.

90. Kandalaft LE, Powell DJ, Coukos G. A phase I clinical trial of adoptive transfe of folate receptor-alpha redirected autologous $T$ cells for recurrent ovarian cancer. Journal of translational medicine. 2012;10:157.

91. Drake CG. Combination immunotherapy approaches. Annals of Oncology. 2012;23:viii41-6.

92. Dunn GP, Bruce AT, Ikeda H, Old LJ, Schreiber RD. Cancer immunoediting: from immunosurveillance to tumor escape. Nature Immunology. 2002:3:991-8.

93. Spranger S, Gajewski T. Rational combinations of immunotherapeutics that target discrete pathways. JITC. 2013;1:16.

94. Duraiswamy J, Kaluza KM, Freeman GJ, Coukos G. Dual blockade of PD-1 and CTLA-4 combined with tumor vaccine effectively restores $T$-cell rejection function in tumors. Cancer Research. 2013:73:3591-603.

95. Hodi FS, Butler M, Oble DA, Seiden MV, Haluska FG, Kruse A, et al. Immunologic and clinical effects of antibody blockade of cytotoxic $T$ lymphocyte-associated antigen 4 in previously vaccinated cancer patients. Proc Natl Acad Sci. 2008;105:3005-10.

96. Kandalaft LE, Powell Jr DJ, Chiang CL, Tanyi J, Kim S, Bosch M, et al. Autologous lysate-pulsed dendritic cell vaccination followed by adoptive transfer of vaccine-primed ex vivo co-stimulated T cells in recurrent ovarian cancer. Oncoimmunology. 2013;2:e22664. 